\title{
Herbicida Paraquat: conceitos, modo de ação e doenças relacionadas
}

\section{Herbicide Paraquat: concepts, mode of action and related diseases}

\author{
Thaismara Martins ${ }^{1}$
}

\section{Resumo}

O Paraquat é um herbicida de contato não seletivo com função de combater plantas daninhas, que atua mediante mecanismos de indução do estresse oxidativo pela produção aumentada de radicais livres associados à depleção dos sistemas antioxidantes do organismo. Esse herbicida pode causar alterações fisiológicas e morte em animais e humanos. Essa revisão pretendeu discutir o modo de ação do Paraquat nas plantas, abordar estudos relacionados aos seus efeitos em insetos pragas e benéficos, em humanos e outros animais. O Paraquat desempenha um papel causal na neurotoxidade, devido o cérebro ter baixos níveis de enzimas antioxidantes e um conteúdo lipídico elevado, tornando-se suscetível ao ataque de espécies reativas de oxigênio. Os radicais livres são formados pela redução incompleta do oxigênio, gerando espécies reativas de oxigênio que apresentam alta reatividade para outras moléculas, principalmente lipídeos, proteínas de membrana celular e DNA. Nos sistemas agrícolas ecologicamente sustentáveis é importante que métodos de controle levem em conta a preservação da diversidade biológica, o baixo impacto ambiental, e a redução das populações de organismos não benéficos, causando o menor efeito nos demais agentes benéficos.

Palavras chave: Controle Químico. Herbicida. Espécies Reativas de Oxigênio. Estresse Oxidativo. Toxicidade.

\begin{abstract}
Paraquat is a no selective contact herbicide with function to combat weeds, which operates through mechanisms of induction of oxidative stress by increased production of free radicals associated with depletion of antioxidant systems of the body. This herbicide can cause physiological changes and death in animals and humans. This literature review sought to discuss the mode of action of paraquat in plants, approach studies related to their effects on pests and beneficial insects, humans and other animals. The Paraquat plays a causal role in neurotoxicity, because the brain has low levels of antioxidant enzymes and high lipid content, making it susceptible to attack by reactive oxygen species. The free radicals are formed by incomplete reduction of oxygen, generating reactive oxygen species that have high reactivity to other molecules, particularly lipids, cell membrane proteins and DNA. Ecologically sustainable agricultural systems is important that control methods take into account the preservation of biological diversity, low environmental impact, and reducing populations of non-beneficial organisms, causing the least effect on other beneficial agents.
\end{abstract}

Keywords: Chemical Control. Herbicide. Reactive Oxygen Species. Oxidative Stress. Toxicity.

${ }^{1}$ Bióloga graduada pela Unipar-Paranavaí, Especialista em Fisiologia Humana e Biotecnóloga aplicada à Agroindústria pela Universidade Estadual de Maringá-UEM. E-mail: thaismara_martins@hotmail.com. 


\section{Introdução}

Sistemas agroecológicos

explorados comercialmente apresentam problemas com insetos praga, plantas daninhas, fungos e bactérias, causando danos econômicos. A incidência destas infestações leva a perda de um grande número de plantas, flores e frutos fazendo-se necessária a utilização de agroquímicos como inseticidas, herbicidas e fungicidas, o que pode provocar além dos efeitos desejáveis de controle, alterações indesejáveis em ecossistemas, pois existem espécies benéficas como predadores, polinizadores e parasitóides que sofrem a ação desses métodos de controle.

Os herbicidas são agroquímicos utilizados para controle das plantas daninhas, porém seu efeito se estende aos insetos e outros invertebrados, empobrecendo a fauna, favorecendo o aumento de infestação por insetos praga, proporcionando perdas econômicas para o produtor, contaminação ambiental e adoecimento de trabalhadores no campo.

O Paraquat é um herbicida muito usado em várias culturas como: fumo, algodão, arroz, café, canade-açúcar, feijão, maça, soja, uva, abacaxi. Este agroquímico é uma molécula aceptora de elétrons, que em plantas expostas a luz leva a sérios prejuízos fisiológicos, com depleção de NADPH e inibição da fixação de $\mathrm{CO} 2$, com consequente produção de superóxidos, os quais promovem a destruição de membranas.

Métodos de identificação da toxicidade do Paraquat sobre a fauna são muito importantes em culturas que utilizam esse herbicida, pois manteria a população de insetos praga e outras infestações abaixo dos níveis de dano econômico sem causar destruição de espécies benéficas, que sofrem os efeitos do estresse oxidativo, afetando seu desenvolvimento. Assim, o objetivo desta revisão foi discutir estudos relacionados ao efeito do herbicida Paraquat, relatando seu modo de ação em plantas, insetos, humanos e outros animais.

\section{Aspecto Geral e Histórico do Herbicida Paraquat}

O paraquat é um sal solúvel em água que desseca rapidamente todo o tecido verde no qual entra em contato, amplamente utilizado em agricultura, não é volátil, explosivo ou inflamável em solução aquosa (PERON et al., 2003). Geralmente é comercializado como Gramoxone ${ }^{\circledR}, \quad$ Gramocil $^{\circledR}, \quad$ Agroquat $^{\circledR}$, Gramuron $^{\circledR}$, Paraquat $^{\circledR}$, Paraquol $^{\circledR}$ e também em misturas com outros princípios ativos, como o Secamato ${ }^{\circledR}$. Os seus sais são eletrólitos fortes que, em solução, dissociam-se em uma grande quantidade de íons positivos e negativos (SERRA et al., 2003).

Seu nome comum é PARAQUATE (Paraquat), com nomenclatura química de 1,1'-dimethyl4,4'-bipyridinium, fórmula bruta com $\mathrm{C}_{12} \mathrm{H}_{14} \mathrm{~N}_{2}$ e fórmula estrutural:

Figura 1 - Fórmula Estrutural do herbicida Paraquat.

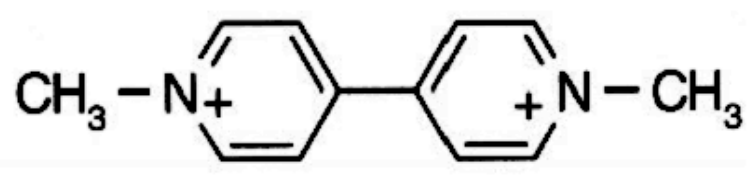

Fonte: SERRA et al., 2003.

Este herbicida pertence ao grupo químico dos bipiridílio, moléculas com atividade relacionada com a formação de radicais superóxidos $\left(\mathrm{O}_{2}-\right)$, cuja detoxificação pela enzima superóxido dismutase, resulta na formação de peróxido de hidrogênio $\left(\mathrm{H}_{2} \mathrm{O}_{2}\right)$, que peroxida lipídios e danifica membranas do cloroplasto e células (VIDAL, 1997).

A aplicação é realizada na pós-emergência das plantas infestantes nas culturas de abacaxi, algodão, arroz, banana, batata, café, cana-de-açúcar, citros, couve, feijão, maçã, milho, seringueira, soja, trigo e uva e como dessecante da cultura de algodão, arroz, batata, cana-de-açúcar, milho e soja (AGÊNCIA NACIONAL DE VIGILÂNCIA SANITÁRIA -ANVISA, 2007). Devido à ação por contato, não é 
eficaz no controle de espécies perenes de reprodução vegetativa, pois possibilita a rebrota das plantas poucos dias depois da aplicação (RODRIGUES; ALMEIDA, 1995).

O Paraquat age na presença de luz, desidratando as partes verdes de todas as plantas com as quais entra em contato, após a aplicação a penetração ocorre quase imediatamente. O local de ação do Paraquat é o cloroplasto contendo os sistemas fotossintéticos das plantas que absorvem a energia luminosa usada para produzir açúcares. Este herbicida é conhecido por agir no sistema da membrana fotossintética, chamado Fotossistema I. Os elétrons livres do Fotossistema I reagem com o íon do Paraquat resultando na forma de radical livre. $\mathrm{O}$ oxigênio rapidamente reconverte esse radical e nesse processo produz superóxido, altamente reativo, que ataca os ácidos graxos insaturados das membranas, rapidamente abrindo e desidratando as membranas e tecidos das células. O processo íon de Paraquatradical livre então se recicla, produzindo maiores quantidades de superóxido até que o suprimento de elétrons livres cesse (CENTRO..., 2013a).

Os estudos mostraram que quando resíduos de Paraquat entram em contato com o solo, o ingrediente ativo do Paraquat é rapidamente absorvido e se liga fortemente a terra e à matéria orgânica do solo se tornando biologicamente inerte e, como resultado, não pode ser absorvido pelas raízes de plantas ou outros organismos. Os solos tratados com Paraquat continuam mantendo um ecossistema ativo na terra, sem efeitos adversos sobre microrganismos e minhocas do solo. O Paraquat não pode ser liberado do solo e nem reativado pela aplicação de água ou de outros agroquímicos. Todos os solos agrícolas possuem alta capacidade de absorver o Paraquat (CENTRO..., 2013a).

\section{Efeito do Estresse Oxidativo nas Células pela Geração de Radicais Livres}

Para Hirata, Sato e Santos (2004) a formação dos radicais livres conduz ao estresse oxidativo, processo que iniciará uma cadeia de reações, originando alterações em proteínas extracelulares e a modificações celulares. O maior dano causado pelo estresse oxidativo é a peroxidação dos ácidos graxos constituintes da dupla camada lipídica da membrana celular resultando em um desequilíbrio no metabolismo aeróbico e uma grave ameaça à homeostase celular.

$\mathrm{Na}$ ausência de oxigênio, o Paraquat sofre uma redução parcial da sua forma catiônica a um radical estável, recuperando na presença de oxigênio a forma catiônica, com consequente produção de ânion superóxido $\left(\mathrm{O}^{-}\right)$. Assim sendo, na presença de oxigênio e de fornecimento contínuo de elétrons, haverá um ciclo de oxidações e reduções, com produção contínua de ânion superóxido. Os efeitos tóxicos do Paraquat explicam-se, em grande parte, por uma reação de oxidação-redução, que compreende a transferência de um elétron para o NADP, com formação de NADPH celular e formas oxidadas potencialmente tóxicas, como o radical superóxido (SERRA et al., 2003).

O oxigênio é completamente reduzido segundo Mittler (2002), por quatro elétrons transportados ao longo da cadeia respiratória, gerando duas moléculas de água. No entanto uma pequena parcela dos elétrons escapa da cadeia respiratória, resultando em uma redução parcial do oxigênio molecular, levando a produção de espécies reativas de oxigênio (ROS) na forma de oxigênio singleto $\left({ }^{1} \mathrm{O}_{2}\right)$, peróxido de hidrogênio $\mathrm{H}_{2} \mathrm{O}_{2}$, radical hidroxila $(* \mathrm{OH})$ e ânion superóxido $\left(\mathrm{O}_{2}^{\bullet-}\right)$.

Para organismos vivos em um ambiente aeróbico, exposição às ROS é contínua e inevitável, gerados intracelularmente através de uma variedade de processos, como subprodutos do metabolismo aeróbico normal, ou como segundo mensageiro na transdução de diferentes caminhos. Essas ROS também podem ser derivados de fontes exógenos, quer diretamente pelas células do meio extracelular, ou produzido como conseqüência da exposição da célula a alguns insultos ambientais. Flutuações na 
quantidade de ROS podem desempenhar importantes funções de regulação, mas quando presentes em altas quantidades e ou níveis sustentados, podem causar graves danos ao DNA, proteínas e lipídios (FINKEL; HOLBROOK, 2000).

Ao nível celular, lesão oxidante provoca um grande espectro de respostas que vão desde a proliferação de parada do crescimento, a senescência e a morte celular. $O$ resultado pode variar significativamente de um tipo de célula para outra. No entanto, independentemente do efeito, em grande parte reflete o equilíbrio entre uma variedade de vias intracelular de sinalização que são ativadas em resposta a injúria oxidativa. Essas vias exercem suas influências através da modulação das atividades de transcrição tendo como efeito mudanças no padrão de expressão gênica. Alguns dos caminhos são claramente ligados à sobrevivência, enquanto outros estão associados à morte celular (MARTINDALE; HOLBROOK, 2002).

\section{Sistema de Defesa Antioxidante}

As enzimas estão envolvidas em muitas reações fisiológicas importantes que em conjunto promovem o estado homeostático. Elas são vitais para a produção regulada de energia celular (ATP) que, por sua vez, é necessária para que ocorram diversos eventos tais como contração muscular, função das células nervosas e transdução de sinais químicos (VANDER et al., 2006).

Um número de sistemas de defesa evoluiu para combater o acúmulo de ROS. Estes incluem várias moléculas não-enzimáticas (glutationa, flavonóides, vitaminas A, C e E), bem como limpadores enzimáticos superóxido dismutase (SOD), catalase, e peróxido de glutationa. Infelizmente, estes mecanismos de defesa não são suficientes para neutralizar a produção destas espécies de ROS, resultando no que é chamado um estado de estresse oxidativo. Uma ampla variedade de doenças tem sido associada ao estresse oxidativo incluindo processos de aterosclerose, diabetes, fibrose pulmonar, doenças neurodegenerativas, artrite, e é acreditado ser um fator importante no envelhecimento (FINKEL; HOLBROOK, 2000).

A SOD corresponde a uma família de enzimas com diferentes grupos protéicos em sua composição, estando presente no citosol e na mitocôndria tendo um papel antioxidante já que catalisa a dismutação do radical superóxido em peróxido de hidrogênio e oxigênio na presença de hidrogênio (FERREIRA; MATSUBARA, 1997).

\section{Efeito do Paraquat em Plantas e seu Modo de Ação}

A exposição das plantas a fatores do ambiente, como variações de temperatura, umidade, agentes biológicos como fungos, bactérias, insetos e herbívoros, faz com que elas necessitem reagir contra esses estresses, possuindo defesas induzidas e préformadas. Essas defesas protegem as plantas de tal forma que podem levar a morte das células próximas ao local onde ocorre o dano ou mesmo levar a autodestruição da planta toda (TAIZ; ZEIGER, 1998).

Várias culturas apresentam competição com plantas daninhas, e uma das alternativas de controle é o uso de herbicidas, entre eles o Paraquat. $\mathrm{O}$ efeito do Paraquat nas folhas das plantas demonstrou que o uso do herbicida proporcionou médias de clorofila e carotenóides menores que aqueles das plantas controle, sendo visíveis os sintomas de clorose intensa e necrose dos tecidos ainda nos primeiros dias após a aplicação Catunda et al., (2005).

As plantas protegem suas células e compartimentos dos efeitos das ROS provocado ou não por herbicidas com o auxílio de enzimas antioxidantes, como superóxido dismutase, ascorbato peroxidase, glutationa redutase, peroxiredoxina, catalase, polifenol oxidase e outros metabólitos que contribuem na resposta da plantas ao estresse (MITTLER, 2002).

O nível e o tipo das ROS são fatores determinantes para o tipo de resposta. O peróxido de hidrogênio e superóxido podem induzir genes diferentes, em 
conjunto ou separadamente, dando mais flexibilidade à sinalização de ROS, em baixas concentrações induzem genes de defesa e resposta adaptativa. Os níveis subletais, contudo, podem levar as plantas a condições de estresses bióticos e abióticos e reduzir seu crescimento, provavelmente como parte de uma resposta adaptacional. Em altas concentrações as ROS levam a um programa de morte celular controlado geneticamente (BREUSEGEM et al., 2001).

Com o objetivo de avaliar a produtividade de feijão, após aplicação do dessecante Paraquat, em diferentes épocas e doses do produto em précolheita Kappes et al., (2012), puderam constatar que o uso de Paraquat até os 35 dias após o início do florescimento (DAF), aumentou de forma linear o percentual de sementes defeituosas e a partir dos 35 DAF a produtividade não foi afetada pela aplicação de Paraquat. Não se recomenda a aplicação desse dessecante em pré-colheita da cultura, a menos que a lavoura apresente maturação desuniforme e esteja infestada por plantas daninhas nesta ocasião, pois na ausência de dessecação, a colheita ocorreu aos 85 dias após a semeadura (50 DAF), e com a utilização de Paraquat como dessecante antecipou a colheita em até sete dias, contudo, esta antecipação do ciclo da cultura foi acompanhada pela redução de $24 \%$ na produtividade, em comparação com a da testemunha.

Magalhães, Durães e Karam (2002) avaliando a eficiência do Paraquat aplicado como dessecante em diversos estádios de desenvolvimento na cultura do milho, constataram que o tratamento aos 14 dias antes da maturação fisiológica, apesar de ter antecipado em dois dias a maturação fisiológica e em quatro dias a colheita, provocou diminuição no peso da matéria seca dos grãos. O uso do Paraquat também resultou em grãos com maior porcentagem de infecção por Fusarium subglutinans (fungo) causador dos grãos ardidos em milho. O produto testado não apresentou diferenças de eficiência para a maioria dos parâmetros avaliados não diferindo também da testemunha nos diferentes estádios. Portanto, o uso desse dessecante na cultura do milho pode trazer benefícios para os agricultores, se os objetivos forem disponibilizar o solo mais cedo para uma nova cultura ou o oferecimento antecipado do produto no mercado.

Giancotti et al., (2012) avaliando o controle de Synedrellopsis grisebachii (agriãozinho) na fase reprodutiva em pastagens, concluiu que o Paraquat proporcionou maior controle sobre essa planta daninha dos 7 aos 14 dias após aplicação, decrescendo não superando os $60 \%$ aos 28 dias após aplicação. A redução pode ser explicada pelo rápido e vigoroso rebrote apresentado pela planta após a perda de área foliar, voltando a infestar.

Com o objetivo de avaliar a eficiência do herbicida Paraquat na dessecação em pré-colheita de mamona Foloni et al. (2011) perceberam que este herbicida reduz expressivamente o teor de água aos 30 dias após aplicação, não sendo o dessecante mais recomendável para esta cultura. Pois o objetivo seria somente uniformizar estruturas reprodutivas, antecipar a colheita levando a lavoura a senescência.

Pereira e Dantas (1995) ao analisarem a qualidade de tubérculos de batata-semente tratadas com Paraquat imersas e injetadas, concluíram que tubérculos injetados com Paraquat apresentam um escurecimento externo com deformação pronunciada da casca, escurecimento da polpa, com necroses, formando cavidades e alterações do tecido, danificando de 58 a $85 \%$ do volume total do tubérculo, reduzindo significativamente o peso fresco das batatas comprometendo a conservação dos tubérculos. Já as batatas que foram somente imersas apresentaram brotação normal, bastante vigorosa e uniforme. Indicando que quando o herbicida for aplicado sob condições que favoreçam sua penetração ou translocação para o interior dos vasos, pode reduzir a qualidade da produção.

O uso eficaz de herbicidas pode reduzir de forma significativa os recursos necessários para controlar ervas daninhas em café, que roubam o rendimento e dificultam as operações de pulverização, adubação e colheita. As plantas daninhas precisam ser administradas em vez de eliminadas, em alguns terrenos o solo nu leva a problemas com a erosão.O 
uso do Paraquat ajuda a manter uma flora de ervas daninhas não competitivas pois extermina somente o crescimento da parte aérea e não afeta a germinação de novas mudas, permitindo, assim, que a vegetação se restabeleça, protegendo o solo e proporcionando habitats para fomentar a biodiversidade. É seguro para os pés de café porque não é sistêmico e é desativado imediatamente ao entrar em contato com o solo, protegendo as raízes e pontos de crescimento, pois não consegue penetrar a casca dos arbustos, o que significa que ele pode ser pulverizado até a base dos mesmos (CENTRO..., 2013b).

\section{Efeitos do Paraquat em Insetos}

Belden e Lydy (2000) afirmam que o uso de herbicidas pode exercer efeitos nocivos sobre a entomofauna, embora a magnitude de respostas possa estar mais diretamente ligada a efeitos indiretos decorrentes de mudanças no habitat. Alguns desses efeitos podem ser devido à perda da cobertura vegetal, exercida pelas plantas daninhas, e pela eliminação da fonte de alimentos de alguns artrópodes, sendo estes mais significativos que os efeitos diretos resultantes da sua composição química. $\mathrm{O}$ fato de que a redução de plantas daninhas pode diminuir a comunidade de artrópodes é confirmada por Araujo et al. (2004) que acrescentam ainda que essa vegetação é utilizada por muitos insetos como abrigo e para alimentação.

Stefanello et al. (2008) avaliaram a seletividade de alguns herbicidas para a cultura de milho, destacando que uma parcela da redução da produtividade dessa cultura se deve às altas populações de insetos e de plantas daninhas, as quais causam danos diretos e indiretos e perdas na produção. Para realizar os testes foi utilizado o Hymenoptera do gênero Trichogramma, que é um inimigo natural de alguns insetos causadores da redução da produtividade, que apresentam como vantagem, o controle dos insetos praga ao parasitálos ainda na fase de ovo. Nesse estudo foi observada alta mortalidade dos adultos de Trichogramma com o herbicida Paraquat, demonstrando que este é nocivo, pois reduziu o parasitismo.

Ao avaliarem a seletividade de herbicidas registrados também para a cultura de milho, Spagnol et al. (2007) conduziram testes de toxicidade de herbicidas para adultos do parasitóide de ovos Trichograma pretiosum (vespinhas). O herbicida Paraquat promoveu redução de parasitismo de 99,95\%, sendo classificado como nocivo aos adultos do parasitóide de ovos T. pretiosum.

O gênero Trichogramma por ser fototrópico positivo apresenta máxima atividade de ovoposição durante o dia estando exposto aos efeitos tóxicos da aplicação de agroquimicos não seletivos, dessa forma podem ser atingidos ou entrar em contado com o herbicida durante o manejo de plantas daninhas ou visando antecipação da colheita podendo afetar negativamente a população desse parasitóide na cultura de milho (SILVA et al., 2007).

Soares, Braz e Busoli (1995) ao determinarem os impactos de herbicidas sobre artrópodes benéficos do algodoeiro, verificaram que surtos de insetos fitófagos como pulgões e mariposas eram provocados pela utilização de herbicidas que reduzem esses invertebrados benéficos. No estudo, foram constados efeitos supressivos dos herbicidas testados sobre os predadores, em relação a joaninhas, tesourinhas predadoras e besouros, porém nenhum dos herbicidas avaliados afetou a população de aranhas.

Há hipótese discordante a respeito do assunto, Norris e Kogan (2000) mencionam que os herbicidas pouco interferem na população dos insetos, entretanto, a alteração da vegetação espontânea é que pode interferir na ocorrência de algumas espécies, especialmente das pragas polífagas.

O impacto causado por diferentes agroquímicos na emergência do parasitóide de ovos Telenomus remus Nixon (vespinha) quando aplicados nas fases de larva e pupa de Spodoptera frugiperda 
(lagarta da folh) seis e 10 dias após o parasitismo, respectivamente foi avaliado por Carmo et al. (2009). No caso dos testes com Paraquat os autores verificaram que não houve alteração na viabilidade do parasitismo em relação ao tratamento testemunha. Os autores concluíram que esse herbicida poderia, portanto, ser utilizado nas fases de larva e pupa em programas de Manejo integrado de pragas (MIP), sem prejuízo para esse inimigo natural.

Saur et al. (2009) estudando a atividade motora de Drosophila melanogaster exposta ao Paraquat, observou que a exposição por $24 \mathrm{~h}$ ao herbicida foi capaz de reduzir a atividade locomotora da mosca tanto jovem quanto adultas. Dias-Santagata et al. (2007) investigaram também em $D$. melanogaster o papel do estresse oxidativo na neurodegeneração e verificaram que níveis aumentados deste, desempenham papel ativo no reforço da neurodegeneração induzida, sugerindo que o dano oxidativo pode desencadear a apoptose.

Após a exposição de D. melanogaster ao Paraquat estudado por Meulener et al. (2006) estes descrevem que houve uma modificação na forma do aminoácido cisteína devido o estresse oxidativo, esta modificação pode levar a inativação funcional, afetando a atividade ou alterando as propriedades bioquímicas das proteínas. Neste estudo foi verificado ainda, que as moscas apresentavam um aumento marcante da sensibilidade ao Paraquat com a idade, sendo mais susceptíveis ao estresse oxidativo, e, portanto o envelhecimento pode contribuir para o desenvolvimento de doenças como a de Parkinson esporádica.

A mosca da fruta $D$. melanogaster tem sido empregada no estudo de neuropatologias humanas, já que as mesmas compartilham inúmeros genes, conservam muitos recursos celulares e moleculares de desenvolvimento e função neuronal e, além disso, há uma crescente evidencia de conservação a nível comportamental, incluindo ritmos circadianos, aprendizagem, memória e sono (RODRIGUES et al., 2009).

\section{Efeito do Paraquat em Animais e Humanos}

O Paraquat é extremamente tóxico, podendo causar intoxicações fatais em humanos e animais. No homem, ele pode ser reduzido pela enzima NADPH (fosfato de nicotinamida adenina dinucleotídeo)-citocromo P450 redutase, com a transferência de um elétron, formando o radical paraquat. Este, por sua vez, em presença de oxigênio oxida-se rapidamente produzindo um ânion radical superóxido e regenerando o paraquat. Desta maneira, ciclos repetidos de redução e reoxidação do herbicida podem ocorrer gerando uma grande quantidade de espécies de oxigênio reduzido que levam o organismo ao estresse oxidativo ou à peroxidação de gorduras (SOUZA; MACHADO, 2003).

Black et al., (2008) compararam a ciclagem do Paraquat em culturas de células de queratinócitos diferenciadas e indiferenciadas, e avaliaram se o estresse oxidativo era induzido por alterações na expressão de antioxidantes. Os autores constataram que o Paraquat é reduzido a um radical nos queratinócitos gerando superóxido e peróxido de hidrogênio, levando a oxidação de proteínas sendo prontamente metabolizado em ambos os tipos de células, este aumento de estresse oxidativo em células da epiderme pode ser um importante mecanismo de toxidade cutânea induzida por Paraquat.

Estudos epidemiológicos têm ligado periodicamente fatores ambientais com maior risco de incidência de doenças, incluindo a vida rural com exposição a produtos químicos agrícolas (BALDERESCH et al., 2003). O Paraquat possui substâncias tóxicas que contribuem para a morte dos neurônios por meio da indução do estresse oxidativo.

A exposição sistemática de roedores ao herbicida em estudo reproduz segundo ManningBog et al., (2002) características patológicas da Doença de Parkinson, incluindo deposição intraneural de proteínas e a degeneração seletiva 
de neurônios dopaminérgicos. Como consequência a neurodegeneração gera disfunções motoras como tremores de repouso e instabilidade postural (KATHTEEN; MAGUIRE-ZEISS, 2008).

Purisai et al., (2007) realizaram testes em ratos para verificar se a administração única de Paraquat ou várias subsequentes, provocariam morte de neurônios. Uma exposição inicial com Paraquat não matou neurônios, mas predispões à degeneração de células dopaminérgicas e uma submissão a nova exposição, levou a morte de células dopaminérgicas em sete dias. Estes resultados são decorrentes das propriedades químicas do herbicida, que é capaz de catalisar a redução de um elétron do Paraquat ao oxigênio molecular formando superóxido que por sua vez causa estresse oxidativo e citotoxidade.

Arbo et al. (2006) avaliaram o efeito do Paraquat sobre a atividade da enzima antioxidante catalase em estruturas cerebrais relacionadas com doenças como Parkinson e Alzheimer em ratos. Não houve lipoperoxidação nas estruturas em estudo, porém, a atividade da enzima foi inibida em 28,5\% no grupo que recebeu $10 \mathrm{mg} / \mathrm{kg}$ de Paraquat. As estruturas escolhidas para o estudo (hipocampo e estriado) são as regiões mais suscetíveis ao estresse oxidativo.

CENTRO..., (2013a) afirma que as deposições de pulverizado de Paraquat após a secagem, não oferecem risco para a saúde de animais domésticos que adentrem os campos pulverizados, ou para animais de criação pastando na vegetação pulverizada com as diluições recomendadas. Esse herbicida se fixa fortemente aos tecidos da planta e, portanto, não é absorvido facilmente pelos animais. Quaisquer traços do produto são rapidamente excretados.

Populações de aves silvestres monitoradas ao longo de um período de cinco anos numa propriedade rural onde o Paraquat era pulverizado muito mais intensivamente do que o habitual, inclusive com aplicação sob cercas vivas e ao longo de cercas, não foram afetadas, nem em termos de densidade de população nem de variedade de espécies. Programas de monitoramento de longo prazo da vida silvestre na França e no Reino Unido demonstraram que o Paraquat não é uma causa significativa de morte de lebres ou de declínio em sua população. Como o paraquat não é biologicamente ativo no solo, ele não tem efeitos adversos sobre a fauna (CENTRO..., 2013a).

D. melanogaster foi empregada como modelo animal em estudo realizado por Rodrigues et al., (2009) com o objetivo de analisar a atividade motora em machos e fêmeas expostos a diferentes concentrações de Paraquat. Moscas machos expostas a $2 \mathrm{mM}$ do herbicida e moscas machos expostas a $15 \mathrm{mM}$ de Paraquat apresentaram uma redução significativa na atividade motora $(p=0,009$ e $\mathrm{p}=0,003$, respectivamente). Já moscas fêmeas expostas a $2 \mathrm{mM}$ de Paraquat não demonstraram redução na atividade motora $(p=0,085)$, porém moscas fêmeas expostas a $15 \mathrm{mM}$ do herbicida apresentaram redução significativa $(p=0,001)$, demonstrando que a $D$. melanogaster fềmea quando exposta à menor concentração de Paraquat não apresentou déficits motores.

Embora insetos não tenham a mesma disposição hormonal que humanos os dados obtidos em D. melanogaster mostram certa analogia com a susceptibilidade ao Mal de Parkinson em humanos, com uma menor incidência da doença em mulheres. Esses resultados indicam que esta suscetibilidade menor a perda dopaminérgica nas fêmeas pode ser detectada em outros grupos animais como os insetos (RODRIGUES et al., 2009).

O herbicida Paraquat é um agente neurotóxico muito empregado, com ação contribuinte ao Mal de Parkinson e de acordo com estudos a exposição experimental ao agrotóxico demonstra ser capaz de induzir a perda significativa de neurônios dopaminérgicos do Sistema nervoso Central (SAUR et al., 2009).

Papini e Andréia (2004) observaram ao avaliarem a ação de minhocas da espécie Eisenia foetida sobre a dissipação do herbicida Paraquat aplicado ao solo 
e em relação a ocorrência de bioacumulação de seus resíduos, que a presença de minhocas não aumentou a dissipação do herbicida durante o período de 90 dias de estudo, porém os animais incorporam resíduos em seus tecidos, podendo comprometer a viabilidade da biota, com tendência de acumulação crescente de Paraquat com o incremento da dose aplicada no solo.

\section{Considerações Finais}

O herbicida Paraquat, discutido nesta revisão, atua sobre o desvio do fluxo de energia captada da luz solar na fotossíntese para a produção de radicais livres altamente reativos, que destroem as membranas celulares e desidrata as folhas rapidamente. Esse efeito pode ser observado nas plantas em poucas horas sob luz solar intensa, devido aos altos níveis de energia que foge do controle.

Possíveis causas da agressividade dos herbicidas sobre as populações de artrópodes, dentre eles os insetos, podem estar relacionadas tanto aos efeitos causados pelo estresse oxidativo como pela falta de alimento, pois o herbicida reduz a comunidade de plantas daninhas presente em cada sistema, das quais os artrópodes se alimentam e utilizam como abrigo, contribuindo assim para o desequilíbrio da entomofauna, ocasionando diminuição das espécies de insetos benéficos.

O próprio metabolismo celular pode gerar Espécies Reativas de Oxigênio, mas a taxa de produção aumenta muito se os tecidos forem expostos a fatores ambientais como o herbicida Paraquat. O dano tecidual causado pelo aumento dos radicais livres e espécies reativas de oxigênio, os quais são instáveis e reagem rapidamente com ácidos graxos, provocam lesão nas membranas, proteínas, DNA e morte celular.

A contaminação do solo por produtos químicos pode ter conseqüências para o meio ambiente e para a fertilidade do solo, pois contaminam partículas que servem de alimento a organismos entre eles a minhoca que possibilita a mistura do solo e constituem a base da alimentação de muitos animais, com a possibilidade de transferência de metabólitos ao longo da cadeia alimentar, levando a magnificação trófica destes compostos.

Diante das atuais preocupações com a preservação da diversidade biológica e com estratégias agrícolas ecologicamente sustentáveis, os impactos desse herbicida sobre plantas e em comunidades de artrópodes, animais e humanos, podem representar importante papel no manejo integrado de pragas, o qual se baseia na adoção de um ou mais métodos de controle que sejam eficientes, de menor custo e interferência no meio ambiente, reduzindo populações de organismos não-benéficos nas lavouras em níveis aceitáveis, com o mínimo de efeito sobre inimigos naturais, decompositores e demais agentes benéficos presentes na área de aplicação.

Deste modo a conscientização de que os inimigos naturais, parasitóides e predadores, servem e atuam de modo aliado no manejo de pragas em culturas, vem a tornar necessária a disponibilizarão de agroquímicos que possibilitem a preservação desses agentes de controle biológico, não devendo ser utilizados enquanto não atingir o nível de dano econômico através de levantamentos e monitoramentos, preservando ainda a saúde dos trabalhadores.

\section{Referências}

AGÊNCIA NACIONAL DE VIGILÂNCIA SANITÁRIA. (ANVISA-BRASIL). Consulta publica n. 60, de 26 de junho de 2007. Disponível em: <www.anvisa.gov.br> Acesso em: 20 jul. 2013.

ARAUJO, R. A.; BADJI, C. A.; CORRÊA, A. S.; LADEIRA, J.A.; GUEDES, R. N. C. Impacto causado por deltametrina em coleópteros de superfície do solo associados à cultura do milho em sistemas de plantio direto e convencional. Neotropical Entomology, Londrina, v. 33, n. 3, maio/jun. 2004. 
ARBO, M. D.; LUDWIG, M.; LUDWIG, L. S.; ALANO, A. S.; ZARDO, V.; STEFFEN, V. M. Efeito tóxico dos praguicidas Maneb e Paraquat sobre a atividade da enzima antioxidante catalase em ratos. Revista de Ciências Farmacêuticas Básica e Aplicada, Araraquara, v. 27, n. 1, p. 57-61, 2006.

BALDERESCHI, M.; DI CARMO, A.; VANNI, P.; GHETTI, A.; CARBONIN, P. AMADUCCI, L.; INZITARI, D. Lifestyle-related risk factors for Parkinson's disease: a population-based study. Acta Neurologica Scandinavica, Copenhagen, v. 108, p. 239-244, 2003.

BELDEN, J. B.; LYDY, M. J. Impact of atrazine on organophosphate insecticide toxicity. Environmental Toxicology and Chemistry, New York, v. 19. n. 9, p. 2266-2274, 2000.

BLACK, A. T.; GRAY, J. P.; SHAAKARJIAN, M. P.; LASKIN, D. L.; HECK, D. E.; LASKIN, J. D. Increased oxidative stress and antioxidant expression in mouse keratinocytes following exposure to paraquat. Toxicology and Applied Pharmacology, San Diego, v. 231, n. 3, p. 384-392, set. 2008.

BREUSEGEM, F. V.; VRANOVÁ, E.; DAT, J. F.; INZÉ, D. The role of active oxygen species in plant signal transduction. Plant Science, Limerick, v. 161, n. 3, p. 405-414, 2001.

CARMO, E. L.; BUENO, A. F.; BUENO, R. C. O. F.; VIEIRA, S. S.; GOBBI, A. L.; VASCO, F. R. Seletividade de diferentes agrotóxicos usados na cultura de soja ao parasitóide de ovos Telenomus remus. Ciência Rural, Santa Maria, v. 39, n. 8, Set 2009.

CATUNDA, M. G.; FREITAS, S. P.; OLIVEIRA, J. G.; SILVA, C. M. M. Efeitos de herbicidas na atividade fotossintética e no crescimento de Abacaxi (Annanas comossus). Planta Daninha, Viçosa, v. 23, n. 1, p. 115121, 2005.

CENTRO de informações sobre o Paraquat. Dados e fatos sobre o Paraquat. Disponível em: <http:// paraquat.com/portugues/banco-de-conhecimentos/ dados-e-fatos-sobre-paraquat> Acesso em: 16 nov. 2013 a.
CENTRO de informações sobre o Paraquat. $O$ café precisa de controle inteligente de plantas daninhas. Disponível em: <http://paraquat.com/portugues/newsand-features/archives/o-caf\%C3\%A9-precisa-decontrole-inteligente-de-plantas-daninhas $>$ Acesso em: 29 jun. 2013 b.

DIAS-SANTAGATA， D.; FULGA. T. A.; DUTTAROY, A.; FEANY, M. B. Oxidative stress mediates tau-induced neurodegeneration in Drosophila. Journal of Clinical Investigation, New York, v. 117, n. 1, p. 236-245, Jan. 2007.

FERREIRA, A. L. A.; MATSUBARA, L. S. Radicais livres: conceitos, doenças relacionadas, sistema de defesa e estresse oxidativo. Revista da Associação Médica Brasileira, São Paulo, v. 43, n. 1, jan./mar. 1997.

FINKEL, T.; HOLBROOK, N. J. Oxidants, oxidative stress and the biology of ageing. Nature, London, v. 408, n. 6809 , p. 239-247, nov. 2000.

FOLONI, J. S. S.; HIRATA, A. C. S.; PEREIRA, D. N.; CARVALHO, M. L. M.; CASAVECHIA, D. Dessecação química em pré-colheita da mamona. Revista Ceres, Viçosa, v. 58, n. 5, p. 665-669, set./out. 2011.

GIANCOTTI, P. R. F.; ALVES, P. L. C. A.; YAMAUTI, M. S.; BARROSO, A. A. M. Controle em pós-emergência e características germinativas de agriãozinho. Planta Daninha, Viçosa, v. 30, n. 2, p. 335340, 2012.

HIRATA, L. L.; SATO, M. E.; SANTOS, C. A. M. Radicais livres e o envelhecimento cutâneo. Acta Farmaceutica Bonaerense, Buenos Aires, v. 23, n. 3, p. 418-424, 2004.

KAPPES, C.; ARF, O.; ARF, M. V.; FERREIRA, J. P.; ALCALDE, A. M.; PORTUGUAL, J. R. Produtividade de feijoeiro de inverno submetidos à dessecação com paraquat na pré-colheita. Revista Ceres, Viçosa, v. 59, n. 1, p. 56-64, jan./fev. 2012.

KATHTEEN, A.; MAGUIRE-ZEISS. $\alpha$-Synuclein: a therapeutic target for Parkinson's disease? Pharmacological Research, London, v. 58, n. 5/6, p. 271280, 2008. 
MAGALHÃES， P. C.; DURÃES， F. O. M.; KARAM, D. Eficiência dos dessecantes Paraquat e Diquat na antecipação da colheita do milho. Planta Daninha, Viçosa, v. 20, n. 3, p. 449-455, 2002.

MANNING-BOG, A. B.; MC CORMACH, A. L.; LI, J.; UVERSKY, V. N.; FINK, A. L.; DI MONTE, D. A. The herbicide Paraquat causes up-regulation and aggregation of B1-synuclein in Mice. Journal of Biological, Baltimore, v. 277, p. 1641-1644, 2002.

MARTINDALE, J.; HOLBROOK, N. Cellular response to oxidative stress: signaling for suicide and survival. Journal of Cellular Physiologi, Philadelphia, v. 192, p. 1-15, 2002.

MEULENER, M. C.; XU, K.; THOMSON, L.; ISCHIROPOULOS, H.; BONINI, N. M. Mutational analysis of DJ-1 in Drosophila implicates functional inactivation by oxidative damage and aging. Proceedings of the National Academy of Sciences, Washington, v. 103, n. 33, p. 12517-12522, ago. 2006.

MITTLER, R. Oxidative stress, antioxidants and stress tolerance. Trends in Plant Science, Oxford, v. 7 , n. 9, p. 405-410, 2002.

NORRIS, R. F.; KOGAN, M. Interactions between, arthropod pests, and their natural enemies in ecosystems. Weed Science, Champaign, v. 48, n. 1/2, p. 94-158, 2000.

PAPINI, S.; ANDRÉA, M. M. Ação de minhocas Eisenia foetida sobre a dissipação dos herbicidas simazina e paraquat aplicados no solo. Revista Brasileira de Ciência do Solo, Viçosa, v. 28, n. 1, jan./ fev. 2004.

PEREIRA, W.; DANTAS, R. L. Qualidade de tubérculos de batata-semente tratados com paraquat e o desenvolvimento de uma metodologia simplificada de detecção de resíduos do herbicida. Planta Daninha, Viçosa, v. 13, n. 1, 1995.

PERON, A. P.; NEVES, G. Y. S.; VALÉRICO, N. C.; VICENTINI, V. E. P. Ação tóxica do herbicida paraquat sobre o homem. Arquivos de Ciências da Saúde da UNIPAR, v. 7, n. 3 set./dez. 2003.
PURISAI, M. G.; McCORMACK, A. L.; CUMINE, S.; LI, J.; ISLA, M. Z.; Di MONTE, D. A. Microglial activation as a priming event leading to paraquat-induced dopaminergic cell degeneration. Neurobiology of Disease, Oxford, v. 25, n. 2, p. 392400, fev. 2007.

RODRIGUES, B. N.; ALMEIDA, F. S. Guia de herbicidas. 3. ed. Londrina: IAPAR, 1995.

RODRIGUES, M. F.; SAUR, L.; BERNARDINO, G. C.; MARTINI, F.; BAGATINI, P. B.; VIANNA, M. R. M. R.; XAVIER, L. L. Variação gênerodependente na atividade motora de Drosophila melanogaster após indução de Parkinsonismo por paraquat. In: SALÃO DE INICIAÇÃO CIENTÍFICA-PONTIFÍCIA UNIVERSIDADE DO RIO GRANDE DO SUL, 10., 2009, Porto Alegre. Anais... Porto Alegre: EDIPUCRS, 2009. p. 297-299.

SAUR, L.; RODRIGUES, M. F.; NIQUE, P. S.; MULlER, C.; BAGATINI, P. B.; VIANNA, M. R. M. R.; XAVIER, L. L. Efeitos do envelhecimento na atividade locomotora de Drosophila melanogaster como modelo de Parkinsonismo. In: SALÃO DE INICIAÇÃO CIENTÍFICA-PONTIFÍCIA UNIVERSIDADE DO RIO GRANDE DO SUL, 10., 2009, Porto Alegre. Anais... Porto Alegre: EDIPUCRS, 2009. p. 283-285.

SERRA, A.; DOMINGOS, F.; PRATA, M. M. Intoxicação por Paraquat. Acta Médica Portuguesa, Lisboa, v. 16, p. 25-32, 2003.

SILVA, A. A.; JAKELAITIS, A.; FREITAS, F. M.; FERREIRA, L. R.; VIVIAN, R. Interação entre herbicida e inseticida sobre o Milho-Pipoca (Zea mays), as plantas daninhas e a lagarta-do-cartucho. Planta Daninha, Viçosa, v. 25, n. 1, p. 181-186, 2007.

SOARES, J. J.; BRAZ, B. A.; BUSOLI, A. C. Impacto de Herbicidas sobre Artrópodes benéficos associados ao Algodoeiro. Pesquisa Agropecuária Brasileira, Brasília, v. 30, n. 9, p. 1135-1140, set. 1995. 
SOUZA, D.; MACHADO, S. A. S. Estudo eletroanalítico do herbicida paraquat em soluções aquosas por voltametria de onda quadrada utilizando ultramicroeletrodos. Química Nova, São Paulo, v. 26, n. 5, set./out. 2003.

SPAGNOL, D.; GRUTZMACHER, A. D.; STEFANELLO JUNIOR, G. J.; GRUTZMACHER, D. D.; FREITAS, D. F.; NORNBERG, D. S. Toxicidade de herbicidas registrados para a cultura do milho a Trichogramma pretiosum Riley, 1879 (Hymenoptera: Trichogrammatidae) em laboratório. In: CONGRESSO DE INICIAÇÃO CIÊNTIFICA: PESQUISA E RESPONSABILIDADE AMBIENTAL, 16., Pelotas. Anais... Pelotas, 2007.

STEFANELLO, J. G. J.; GRUTZMACHER, A. D.; GRUTZMACHER, D. D.; LIMA. C. A. B.; DALMOZO, D. O.; PASCHOAL, M. D. F. Seletividade de herbicidas registrados para a cultura do milho a adultos de Trichogramma pretiosum (Hymenoptera: Trichogrammatidae). Planta Daninha, Viçosa, v. 26, n. 2, abr./jun. 2008.

TAIZ, L.; ZEIGER, E. Plant defenses: surface protectants and secondary metabolites. In: Plant Physiology. Sunderland: Sinauer Associates, 1998. p. 347-376.

VANDER, A. J.; SHERMAN, J. H.; LUCIANO, D. S. Estrutura celular e função protéica. In:

Fisiologia Humana: os mecanismos das funções corporais. 9. ed. Rio de Janeiro: Guanabara Koogan, 2006. p. 85-91.

VIDAL, R. A. Herbicidas: mecanismos de ação e resistência de plantas. Porto Alegre: Palotti, 1997. 